\title{
FEASIBILITY OF THE USE OF WIND ENERGY GENERATION AT SEWAGE PLANTS IN MONTEVIDEO CITY.
}

\author{
Ventura Nunes, José Cataldo, Gonzalo Casaravilla. \\ Work Group on Renewable Energies. \\ Facultad de Ingeniería, \\ Julio Herrera y Reissig 565 - (11300) \\ Montevideo, Uruguay.
}

e-mail: nunes@iie.edu.uy, jcataldo@fing.edu.uy, gcp@iie.edu.uy.

\begin{abstract}
Due to environmental concerns, the Montevideo City authorities funded a feasibility study of the use of wind turbines in several sewage works. The generators, $150 \mathrm{~kW}$ or more each one, will be connected to the grid. The study began with the assessment of wind resource at each site, using the wind data series available at meteorological stations adjusted to the exposure parameters related to the kind of soil upstream in the different directions. The hourly power demand of the plants was modelled and forecast for the next fifteen years. The visual and acoustic impacts of the wind turbines were considered.
\end{abstract}

Different wind turbine arrays were selected to supply the energy needed in each plant. The feasibility study was done assuming two possibilities: the excess wind energy was either sold to the utility or not. The results in Punta Brava site are shown.

The best internal rate of return values obtained were about $8 \%$, which are considered to be good rates, attending the constrains assumed. In short term, city authorities decided to install wind turbines at Punta Brava

\section{KEYWORDS}

Wind Power Assessment, Environmental Impact, Renewable Energies, Feasibility.

\section{INTRODUCTION}

Montevideo City has several sewage works. Most of them are located on the coast of Rio de la Plata, including the biggest in Punta Brava. In a first approach, all these plants were considered as possible sites for the installation of wind turbines.

It was the first time wind energy was ever considered for implementation in an industrial plant in a city in this country. Wind turbines of less than $100 \mathrm{~kW}$ output were discarded due to their different technical characteristics and their higher cost per $\mathrm{kW}$. It was assumed that most of the energy was going to be used in the plant. In consequence, the smaller plants were dismissed. In other two sites, there was no room for windmills on the shore and for urban reasons it was not possible to place them on the other side of the road. 
Table 1. Power rates of transformers and pumps.

\begin{tabular}{lll}
\hline Site & Transformers [kVA] & Pumps [kW] \\
\hline Punta Brava & $1250+315$ & $3 \times 186.5+2 \times 56$ \\
Punta Gomensoro & 630 & $3 \times 112$ \\
Chacarita & 800 & $4 \times 150$ \\
\hline
\end{tabular}

Table 1 shows the power rates of the transformers and pumps installed in three of the plants. For these plants the wind resource and the visual and acoustic impact were assessed and the feasibility study was performed.

\section{WIND SPEED AND DIRECTION}

The analysis of wind characteristics of each site was based in the mean wind speed and direction series supplied by weather stations close to the sites, and the type of exposure to the wind which depends on the different directions. The windmills are mostly immersed in the logarithmic sublayer of the atmospheric boundary layer (ABL). This happens when the upstream terrain is of sea or rural type. In this part of the atmospheric flux, the distribution in height of the mean speed is ruled by the following logarithmic equation (Simiu \& Scanlan, (1986)).

$$
U=\frac{u^{*}}{k} L \frac{z-d}{z_{0}}
$$

$\mathrm{U}$ is the mean speed at height $\mathrm{z}, \mathrm{d}$ is the zero displacement plane height and $\mathrm{z}_{0}$ is the roughness length. Each type of terrain presents different values of the characteristic parameters. The mean wind speed figures were measured at $10 \mathrm{~m}$ height.

The wind turbines characteristic curves, mean wind speed versus power output, consider the mean wind speed at its axis height so it is necessary to estimate the speed values at this height. The estimation was performed using equation (1) and the characteristic parameters of the site where the measures were obtained and those of wind turbine selected site.

For certain wind directions and a few of the considered sites, the wind turbines are located in the wake of neighbouring buildings with heights of the same order as those of the windmills. The flux in these cases depends strongly on the geometrical shape of those obstacles. In this case, the mean wind speed was obtained from data acquired at the wind tunnel tests and measurements taken in the field.

\section{PUNTA BRAVA'S WIND CHARACTERISTICS}

Punta Brava, a point that enters into the estuary, is located in the southern part of Montevideo City. For directions WNW, W, WSW, SW, SSW, S, SSE, SE, ESE, E, ENE, the upstream terrain is of the sea type. For directions NW, NNW, the terrain is of the rural type, and for directions N, NNE and NE, the terrain is of the city type. The values of the characteristic parameters $\mathrm{z} 0$ and $\mathrm{d}$ for terrain type rural are $5 \mathrm{~cm}$ and $0 \mathrm{~m}$ respectively, for sea type 0,3cm and 0m, and for city type 200 $\mathrm{cm}$ and 20m. (Counihan, J., (1975), ESDU, (1985), Wang, Z.Y. et al. (1996))

Figures 1 and 2 present the mean wind speed and direction histograms, estimated at Punta Brava. The height is $30 \mathrm{~m}$ above ground. The results of this analysis were the estimated wind data hourly series for each selected wind turbine axis height. 


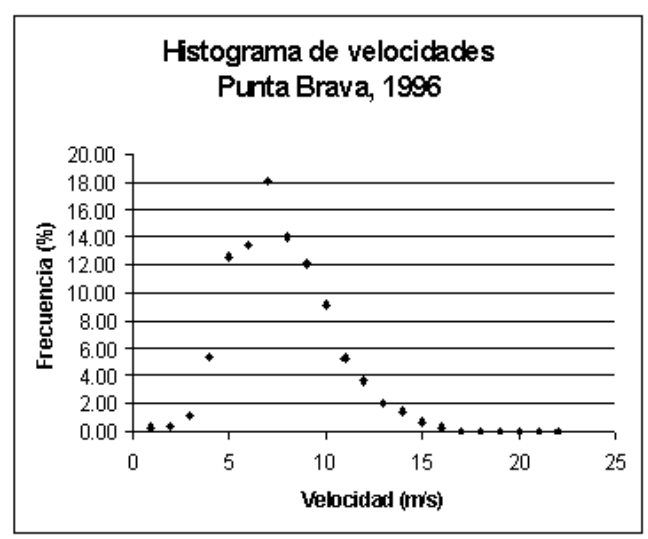

Fig. 1. Wind speed histogram.

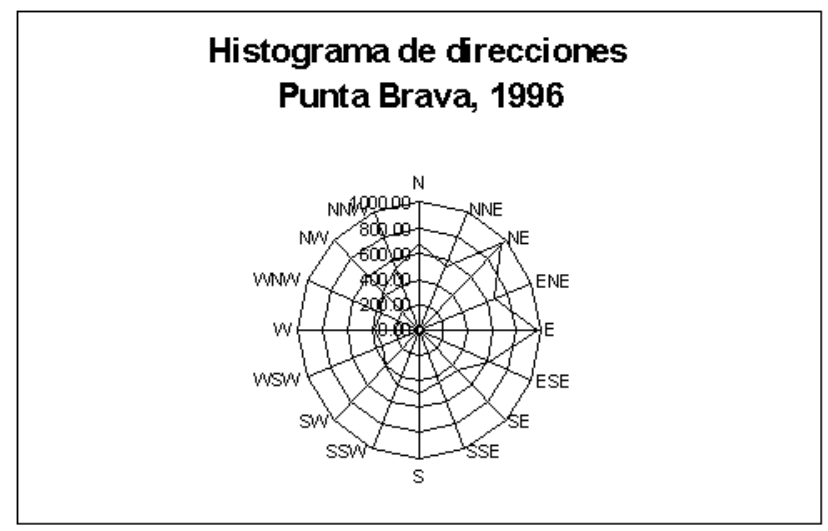

Fig. 2. Wind direction histogram.

\section{ACOUSTIC EMISSIONS}

A study of acoustic emissions was performed at all the sites considered. In particular, at Punta Brava, where the smaller distance between windmills and surrounding buildings is $800 \mathrm{~m}$, values of $\mathrm{Lp}=26.4 \mathrm{~dB}$ were obtained. This level of noise is so small compared to the registered noise values in the field that, even during the night, it would remain unnoticeable.

\section{FEASIBILITY STUDY: SCENARIOS CONSIDERED.}

The scenarios for the feasibility study were established considering two points of view: the economical one and the wind resource.

\section{Economic aspects}

The internal rate of return was calculated in a fifteen years period. The expected life of the wind turbine is assumed to be twenty years. The VAT was considered only in maintenance and insurance costs and included in the electric service tariff. This tariff has three different energy prices during the day and a power charge. In the country, the prices paid for energy, thermal or renewable, by the electric system in this type of connection are not yet determined, although the recent regulatory law allows this kind of trade. Moreover, there is not a policy for the "green market" of electricity. To calculate the internal rate of return, several prices were assumed, all of them in the order or less than similar regional prices. Also, the possibility of not selling was considered. The already mentioned assumption that most of the energy will be used in the plant was fixed for these reasons.

\section{Use of the wind resource}

Using the estimated wind data hourly series and the curves mean wind speed versus power output, the hourly power output of the wind turbines selected was calculated through the year. The hourly power demand of each plant was modelled and forecasted for the next fifteen years.

The pertaining data available were: the historical daily series of water volume pumped during the last four years, the historical hourly series for a typical day of each month during the same four years, the hourly electric and hydraulic measurements registered during several days, the works planned at the sewerage and the historical annual growth rate.

The hourly power demand series were estimated using for each day of each month the hourly demand of the typical day of this month. For each site, different arrays of wind turbines were selected considering the power demand of the plant, the area available and the constrains about selling the excess energy already discussed.

\section{$\underline{\text { Results obtained in Punta Brava }}$}

Two different wind turbines were selected. One of them has an output of $225 \mathrm{~kW}$, and the other of $150 \mathrm{~kW}$. Arrays with two to four wind turbines were considered. 
The values of the internal rate of return assuming that energy is sold at $40 \mathrm{U} \$ / \mathrm{MWh}$ and that energy is not sold at all, are shown in table 2. The calculus was performed at constant prices in dollars. Moreover, to show the influence of the electrical service tariff, an overprice of $10 \%$ in fifteen years is also considered in the same table.

Table 2. Internal rate of return.

\begin{tabular}{cccccc}
\hline Array & kW & \multicolumn{2}{c}{ Overprice 10\% } & \multicolumn{2}{c}{ Constant tariff } \\
selling at & not selling & selling at & notling \\
& & 40 US/MWh & & $5.2 \%$ & $4.8 \%$ \\
\hline 2xA & 450 & $6.2 \%$ & $5.8 \%$ & $5.3 \%$ & $3.6 \%$ \\
3xA & 675 & $6.3 \%$ & $4.6 \%$ & $5.3 \%$ & $2.0 \%$ \\
4xA & 900 & $6.2 \%$ & $2.9 \%$ & $7.6 \%$ & $7.3 \%$ \\
2xB & 300 & $8.6 \%$ & $8.4 \%$ & $7.8 \%$ & $6.3 \%$ \\
3xB & 450 & $8.8 \%$ & $7.3 \%$ & $7.8 \%$ & $4.6 \%$ \\
4xB & 600 & $8.8 \%$ & $5.6 \%$ & & \\
\hline
\end{tabular}

In table 3, the balance in MWh during the last year of the study and the amounts in dollars that would be paid to the utilities if the wind turbines were not installed and if the different selected arrays were in service, are shown.

Table 3. Energy balance and expenses with and without project.

\begin{tabular}{|c|c|c|c|c|c|c|c|}
\hline Array & $\mathbf{k W}$ & $\begin{array}{c}\text { Generation } \\
\text { (MWh) }\end{array}$ & $\begin{array}{r}\text { Demand } \\
(\mathrm{MWh})\end{array}$ & $\begin{array}{c}\text { Bought to } \\
\text { grid } \\
\text { (MWh) }\end{array}$ & $\begin{array}{l}\text { Sold to } \\
\text { grid } \\
(\mathrm{MWh})\end{array}$ & $\begin{array}{c}\text { With wind } \\
\text { energy } \\
\text { U\$Sx1000 }\end{array}$ & $\begin{array}{c}\text { Without wind } \\
\text { energy } \\
\text { U\$Sx1000 }\end{array}$ \\
\hline $2 \times A$ & 450 & 1596 & 4435 & 2856 & 17 & 133 & 201 \\
\hline $3 \times A$ & 675 & 2394 & 4435 & 2236 & 195 & 98 & 201 \\
\hline $4 \times A$ & 900 & 3192 & 4435 & 1838 & 595 & 64 & 201 \\
\hline $2 \times B$ & 300 & 1568 & 4435 & 2874 & 7 & 134 & 201 \\
\hline $3 \times B$ & 450 & 2352 & 4435 & 2206 & 123 & 100 & 201 \\
\hline $4 \times B$ & 600 & 3136 & 4435 & 1772 & 473 & 66 & 201 \\
\hline
\end{tabular}

The capacity factor of wind turbine A was $41 \%$ and for wind turbine B $60 \%$.

\section{CONCLUSIONS}

The use of wind energy in some sewage works of Montevideo city is feasible, in particular, at the biggest one in Punta Brava even with the constrains indicated. The economical feasibility depends strongly on the prices that could be obtained for the excess energy. This price would also allow the use of wind turbines with bigger output with important scale economies. In short term, city authorities decided to install wind turbines at Punta Brava driven by economic convenience and the promotion of a clean source of energy in a country where the wind resource is abundant.

\section{REFERENCES}

Counihan, J., (1975), “Adiabatic atmospheric boundary layers: A review and analysis of data from period 18801972", Atmospheric Environment, vol.79, 871-905.

ESDU, (1985), "Characteristics of atmospheric turbulence near the ground. Part II: single point data for strong winds (neutral atmosphere) “, Item Number 85020.

Gaja, E., (1996) "Ingeniería Acústica Ambiental”, Departamento de Física Aplicada, Universidad Politécnica de Valencia, SPUPV. 96.5631.

Harris,C.M. (1995)."Manual de medidas acústicas y control de ruido”, 3ra. Ed., McGraw Hill, España.

Simiu \& Scanlan, (1986 ), "Wind Effects on structures: An introduction to wind engineering",John Wiley \& Sons.

Wang, Z.Y., Plate,E.J., Rau, M. \& Keiser, R., (1996), “Scale effects in wind tunnel modelling”, Journal of Wind Engineering and Industrial Aerodynamics, 61, 113-130. 